\title{
Pengaruh Kompensasi Dan Lingkungan Kerja Terhadap Kinerja Karyawan PT. Bank QNB Indonesia
}

\author{
Jason Sebastian dan Kurniati W. Andani \\ Program Studi Manajemen, Fakultas Ekonomi dan Bisnis \\ Universitas Tarumanagara Jakarta \\ Email: sebastianjason91@gmail.com
}

\begin{abstract}
The purpose of this study has two objectives, namely to find out whether there is a compensation effect on employee performance and the influence of the work environment on employee performance. Researchers took a sample of 75 respondents at PT Bank QNB INDONESIA branch of SCBD using questionnaires. This research method uses SmartPLS. Hypothesis testing conducted in this study is that there is a positive, significant and not significant effect on compensation and work environment on employee performance.
\end{abstract}

Keywords: compensation, work environment and performance.

\begin{abstract}
Abstrak: Tujuan dari penelitian ini memiliki dua tujuan, yaitu mengetahui apakah terdapat pengaruh kompensai terhadap kinerja karyawan dan pengaruh lingkungan kerja terhadap kinerja karyawan .Peneliti mengambil sampel sebanyak 75 responden pada PT Bank QNB INDONESIA cabang SCBD dengan menggunakan kuisioner. Metode penelitian ini menggunakan SmartPLS. Pengujian hipotesis yang dilakukan dalam penelitian ini adalah terdapat pengaruh positif, signifikan dan tidak sifgnifikan terhadap kompensasi dan lingkungan kerja terhadap kinerja karyawan.
\end{abstract}

Kata kunci: Kompensasi, lingkungan kerja dan kinerja.

\section{LATAR BELAKANG}

Keberadaan sumber daya manusia di dalam suatu perusahaan memegang peranan sangat penting karena tenaga kerja memiliki peran yang besar untuk menjalankan aktivitas perusahaan. Potensi setiap sumber daya manusia yang ada dalam perusahaan harus dapat dimanfaatkan dengan sebaik-baiknya agar dapat memberikan hasil yang maksimal..Kompensasi merupakan peranan yang sangat penting untuk meningkatkan kinerja para karyawan dikarenakan salah satu alasan utama seseorang untuk bekerja di suatu perusahaan adalah untuk memenuhi keperluan hidupnya melalui imbalan atau kompensasi yang diterima atau didapatkan dari tempat mereka bekerja .Kompensasi juga dapat diartikan sebagai bentuk penghargaan yang diberikan oleh perusahaan kepada karyawan sebagai tanda terima kasih atau pembalasan jasa atas kontribusi yang telah diberikan karyawan kepada perusahaan tersebut.

Salah satu cara yang dapat meningkatkan kualitas perusahaan adalah dengan menghubungkan kompensasi dan kinerja dari karyawan tersebut dikarenakan bahwa di dalam suatu perusahaan, karyawan ditujukan untuk memajukan sebuah perusahaan tersebut.Salah satu indikatornya adalah dengan kinerja karyawan yang baik dan maksimal sehingga dapat mencapai target yang perusahaan inginkan 
Menurut penelitian Rachmawati (2009) dikatakan bahwa suatu organisasi atau perusahaan mempunyai keinginan dan juga harapan untuk mengalami perubahan dan peningkatan kualitas kerja perusahaan , yang mengarah pada kemajuan dan perkembangan menuju yang lebih baik. Setiap perusahaan akan berusaha meningkatkan dan mengembangkan perusahaan dengan mengadakan berbagai kegiatan guna meningkatkan kinerja para karyawan. Kinerja adalah hasil kerja yang dapat dicapai oleh seseorang atau sekelompok orang dalam suatu organisasi, sesuai dengan wewenang dan 2 tanggung jawab masing-masing dalam rangka mencapai tujuan organisasi yang bersangkutan secara legal, tidak melanggar hukum, dan sesuai dengan moral maupun etika

Selain kompensasi,. Lingkungan kerja merupakan suatu alat utama dan juga tempat yang berpengaruh terhadap kinerja karyawan jika lingkungan yang ada diperusahaan itu baik. Lingkungan kerja yang menyenangkan bagi karyawan melalui pengikatan hubungan yang harmonis dengan atasan maupun bahawan, serta didukung oleh sarana dan prasarana yang memadai yang ada ditempat bekerja akan membawa dampak positif bagi karyawan, sehingga kinerja meningkat. Suatu perusahaan mempunyai tujuan untuk mendapatkan upah guna memenuhi kebutuhan hidupnya, begitu pula dengan adanya lingkungan kerja yang baik maka akan tercipta suasana kerja yang menyenangkan dilingkungan perusahaan.. Setiap perusahaan pasti akan menciptakan lingkungan kerja yang betujuan untuk membuat karyawan menjadi nyaman dan lebih giat bekerja di suatu perusahaan tersebut.

Menurut Nitisemito (2002: 25) : lingkungan kerja adalah segala sesuatu yang ada di sekitar para pekerja dan dapat memengaruhi dirinya dalam menjalankan tugas yang di bebankan. Dari pernyataan di atas, dapat disimpulkan bahwa lingkungan kerja adalah segala sesuatu yang berada di sekitar karyawan baik fisik dan juga non fisik yang mempengaruhi kinerja karyawan. Lingkungan kerja mensertakan pelayanan yang diberikan oleh karyawan kerja di sekitar dan untuk menciptakan lingkungan kerja yang baik, perusahaan juga harus memberikan pelayanan yang baik dari perusahaan yang dapat memberikan kepuasan kerja karyawan. Dengan kepuasan kerja yang dimiliki karyawan dari pelayanan yang baik dari perusahaan. Karyawan pun dapat memberikan hasil yang maksimal bagi perusahaan 'Kinerja merupakan gambaran mengenai tingkat pencapaian suatu program kegiatan atau kebijakan dalam mewujudkan sasaran, tujuan, visi, dan misi yang dimulai dari perencanaan strategis dari suatu organisasi. Kinerja dapat diartikan sebagai hasil yang dicapai seseorang baik kualitas maupun kuantitas sesuai dengan tanggung jawab yang diberikan kepadanya. Selain itu kinerja seseorang dipengaruhi oleh tingkat pendidikan, inisiatif, pengalaman kerja, dan motivasi karyawan

\section{KAJIAN TEORI}

Hasibuan (2002:132) menyatakan bahwa"kompensasi adalah semua pendapatan yang berbentuk uang atau barang langsung atau tidak langsung yang diterima karyawan sebagai imbalan atas balas jasa yang diberikan kepada perusahaan". Menurut Dessler dalam Subekhi (2012:175) kompensasi karyawan adalah setiap bentuk pembayaran atau imbalan yang diberikan kepada karyawan dan timbil dari diperkerjannya karyawan itu. Menurut Pangabean dalam Subekhi (2012:176) kompensasi adalah setiap bentuk penghargaan yang diberikan karyawan sebagai balas jasa atas kontribusi yang mereka berikan kepada organisasi.

Menurut Sedarmayanti (2001:21) mendefinisikan lingkungan kerja adalah keseluruhan alat perkakas dan bahan yang dihadapi, lingkungan sekitarnya dimana seseorang bekerja, 
metode kerjanya, serta pengaturan kerjanya baik sebagai perseorangan maupun sebagai kelompok. Menurut Render \& Heizer (2001:239) lingkungan kerja merupakan lingkungan fisik tempat karyawan bekerja yang mempengaruhi kinerja, keamanan, dan mutu kehidupan kerja mereka. Menurut Nitisemito (1996:106) lingkungan kerja merupakan kondisi dari segala sesuatu yang terdapat di sekitar tempat bekerja karyawan yang mampu memberikan pengaruh bagi dirinya dalam melaksanakan pekerjaannya.

Menurut Simamora (2004:339), kinerja adalah "kadar pencapaian tugas-tugas yang membentuk pekerjaan karyawan dan merefleksikan seberapa baik karyawan memenuhi persyaratan sebuah pekerjaan Menurut Wibowo (2016:44), kinerja merupakan tanggung jawab setiap individu terhadap pekerjaan, membantu mendefinisikan harapan kinerja, mengusahakan kerangka kerja bagi supervisor dan pekerja yang saling berkomunikasi.

\section{Kaitan Antar Variabel-variabel}

Pengaruh Kompensasi terhadap kinerja karyawan. Menurut Firmandari (2014) dari hasil pengujian kompensasi berpengaruh positif terhadap kinerja karyawan.Kompensasi yang diberikan oleh perusahaan akan berdampaak pada kinerja karyawan, besar kecilnya kompensasi yaitu berupa gaji, upah, insentif atau kompensasi tidak langsung akan sangat mempengaruhi kinerja karyawan Selanjutnya menurut Sadzwina dan Gilang (2015) yang menyatakan bahwa terdapat pengaruh yang positif dan signifikan antara kompensasi dengan kinerja karyawan.Dikarenakan pemberian kompensasi yang tingga dapat meningkatkan kinerja dari karyawan tersebut. Menurut Sopiah (2008) kinerja dipengaruhi juga oleh lingkungan kerja.. Situasi lingkungan yang kondusif, misalnya dukungan dari atasan, teman kerja, sarana dan prasarana yang memadai akan menciptakan kenyamanan tersendiri dan akan memacu kinerja yang baik. Menurut Wardani (2009) bahwa kompensasi berpengaruh positif terhadap kinerja. Kompensasi juga mengandung adanya hubungan yang sifatnya professional salah satu tujuan utamanya adalah mendapatkan imbalan agar dapat mencukupi kebutuhan, sementara disisi perusahaan mereka membayar karyawan agar para karyawan dapat menjalankan pekerjaan sesuai dengan keinginan dan harapan perusahaan agar dapat memajukan jalannya perusahaan

Pengaruh Lingkungan kerja terhadap kinerja karyawan. Menurut penelitian Emad Y. Masoud,PhD (2013) dan Tahreer Abu Hmeidan,MBA (2013) melakukan penelitian dengan tujuan untuk mengeksplorasi dampak potensial dari lingkungan kerja pada kinerja karyawan garis depan. Menurut peneltian yang dikemukakan oleh Robbins (2002:36), bahwa para karyawan menaruh perhatian yang besar terhadap lingkungan kerja mereka, baik dari segi kenyamanan pribadi maupun kemudahan melakukan pekerjaan dengan baik Menurut penelitian yang dilakukan oleh Winardi (2007) lingkungan kerja merupakan suatu alat ukur yang akan berpengaruh terhadap kinerja pegawai jika lingkungan kerja yang ada pada instansi itu baik. Menurut penelitian yang dilakukan oleh Vita dan Suwarto (2015) melakukan penelitian dengan tujuan untuk untuk mengetahui pengaruh gaya kepemimpinan, budaya organisasi, dan lingkungan kerja terhadap kinerja guru dan karyawan pada Yayasan Tri Asih Jakarta dijelaskan bahwa lingkungan kerja memiliki hubungan yang positif dan signifikan terhadap kinerja

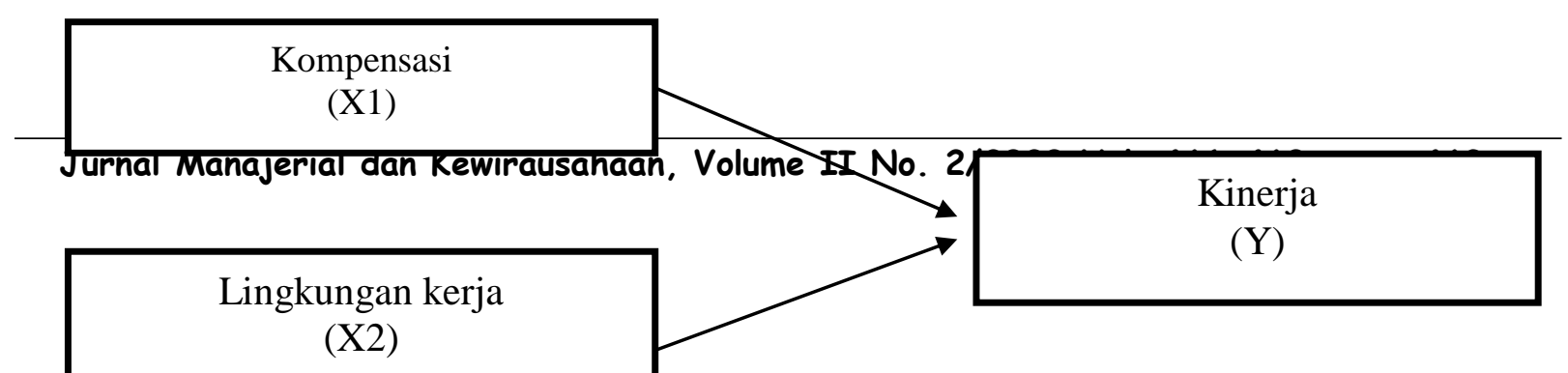


Gambar 2.1. Kerangka Pemikiran

Berdasarkan kerangka pemikiran diatas maka hipotesis penelitian ini adalah sebagai berikut:

H1: Terdapat pengaruh positif dan tidak signifikan kompensasi terhadap kinerja karyawan. H2: Terdapat pengaruh positif dan signifikan lingkungan kerja terhadap kinerja karyawan.

\section{METODE PENELITIAN}

Pada metode penelitian ini, desain penelitian yang digunakan dalam penelitian ini adalah desain penelitian konklusif. Penelitian konklusif menurut Malhotra (2010: 104) disebutkan bahwa riset yang dirancang untuk memudahkan pembuat keputusan dalam menentukan, mengevaluasi, serta memilih rangkaian tindakan yang harus diambil pada situasi tertentu. Populasi adalah karyawan PT.Bank QNB INDONESIA cabang SCBD sebanyak 75 orang.

Data dianalisis menggunakan PLS-SEM dimana data diolah dengan program software SmartPLS 3. Pertama, pengolahan dilakukan pada outer model untuk menguji validitas (konvergen dan diskriminan) dan reliabilitas. Uji validitas konvergen dilihat dari nilai outer loadings di antara 0,5-0,7 kemudian AVE > 0,5. Selanjutnya untuk uji validitas diskriminan, beracuan pada Fornell-Larcker Criterion dan Cross Loadings (Garson, 2016). Kemudian pada analisis reliabilitas, beracuan pada nilai cronbach's alpha dan composite reliability > 0,7 (Ghozali dan Latan, 2015:75).

Kedua, pengolahan dilakukan pada inner model untuk menguji hipotesis yang telah dihasilkan. Sebelum pengujian hipotesis, pertama dilakukan pengujian hubungan antar konstruk dengan melihat nilai R-square $\left(\mathrm{R}^{2}\right)$ dengan kriteria $(1-0,75)$ "bersifat kuat", $(0,74-0,5)$ "bersifat moderat", dan $(0,49-0,25)$ "bersifat lemah" (Ghozali dan Latan, 2015:78), nilai $\mathrm{Q}$-square $\left(\mathrm{Q}^{2}\right)$ dengan kriteria $\mathrm{Q}^{2}>0$ "memiliki kemampuan prediksi" (Chin, 2010), dan nilai GoF (Goodness of Fit) dengan kriteria 0,1 "kelayakan model kecil", 0,25 "kelayakan model sedang", dan 0,36 "kelayakan model besar" (Tenenhaus, 2005). Selanjutnya pengujian hipotesis, untuk melihat pengaruh yang terjadi lihat (positif/ negatif) dari coefficient yang dihasilkan, dan menggunakan t-statistics $>1,645$ (hipotesis tidak ditolak) dan $p$-values < 0,05 (hipotesis signifikan) (Haryono, 2017:40).

\section{Hasil Uji Statistik}

Hasil Uji validitas. Pada hasil validitas konvergen, didapatkan semua angka $>0,5$ pada nilai outer loadings untuk setiap pernyataannya, dan didapatkan semua angka $>0,5$ pada 
nilai Average Variance Extracted / AVE maka pernyataan yang digunakan sudah valid secara validitas konvergen. Selain itu, pada hasil validitas diskriminan, peneliti menggunakan nilai Cross Loadings dimana nilai korelasi antara pernyataan terhadap variabel nya sendiri harus lebih besar daripada pernyataan terhadap variabel lainnya berdasarkan hasil kalkulasi SmartPLS 3, didapatkan semua angka pada pernyataan terhadap variabel-nya sendiri lebih besar daripada terhadap variabel lainnya maka pernyataan sudah valid secara validitas diskriminan.

Hasil Uji reliabilitas. Pada hasil reliabilitas, maka berdasarkan hasil yang dikalkulasi oleh program SmartPLS 3, didapatkan semua angka pada nilai Cronbach's Alpha untuk setiap pernyataannya adalah > 0,7 dan pada nilai Composite Reliability didapatkan semua angka untuk setiap pernyataannya adalah $>0,7$. Maka pernyataan yang digunakan dalam penelitian ini sudah reliabel berdasarkan kedua nilai reliabilitas, yakni Cronbach's Alpha dan Composite Reliability.

Hasil Uji $\boldsymbol{R}$-Square $\left(\mathbf{R}^{\mathbf{2}}\right)$ dan F square. Hasil R-square adalah sebesar 0.782 yang berarti $78,2 \%$ variabel Kinerja Karyawan dapat dijelaskan oleh variabel Kompensasi dan Lingkungan Kerja Sedangkan sisanya sebesar 21,8\% akan dijelaskan oleh variabel selain Kompensasi dan Lingkungan Kerja. Hasil uji F square kompensasi memiliki pengaruh yang dikategorikan tidak berarti (0.0-3) terhadap kinerja karyawan, begitu juga dengan lingkungan kerja yang dikategorikan kuat (0.536) terhadap kinerja karyawan

\section{Hasil Uji Hipotesis}

Tabel 1. Hasil Uji Hipotesis (Bootstrapping)

\begin{tabular}{|l|c|c|c|c|c|}
\hline & $\begin{array}{c}\text { Original } \\
\text { Sample(O) }\end{array}$ & $\begin{array}{c}\text { Sample } \\
\text { Mean } \\
(\mathbf{M})\end{array}$ & $\begin{array}{c}\text { Standard } \\
\text { Deviation } \\
\text { (STDEV) }\end{array}$ & $\begin{array}{c}\text { T-Statistic } \\
(\mid \mathbf{O} / \text { STDEV|) }\end{array}$ & $\begin{array}{c}\text { P } \\
\text { Values }\end{array}$ \\
\hline $\begin{array}{l}\text { Kompensasi } \\
\text { Kinerja } \\
\text { Karyawan (Y) }\end{array}$ & 0,063 & 0,058 & 0,160 & 0,397 & 0,692 \\
\hline $\begin{array}{l}\text { Lingkungan } \\
\text { Kerja } \rightarrow \text { Kinerja } \\
\text { Karyawan }\end{array}$ & 0,826 & 0,838 & 0,145 & 5,694 & 0,000 \\
\hline
\end{tabular}

Sumber: Hasil Olah Data pada SmartPLS3

\section{DISKUSI}

Hasil pengujian variabel kompensasi terhadap kinerja karyawan memiliki tstatistics sebesar 0,063 dimana nilai tersebut lebih kecil dari nilai t-table >1.96. Dapat diambil kesimpulan bahwa terdapat pengaruh yang tidak signifikan antara kompensasi dengan kinerja karyawan dan hipotesis ketiga (H1) tidak didukung. Hasil penelitian ini juga sesuai dengan Suharyanto, Nugraha, dan Permana (2015) menyatakan bahwa kompensasi memiliki pengaruh positif dan tidak signifikan terhadap kinerja karyawan. Hasil pengujian variabel lingkungan kerja terhadap kinerja karyawan memiliki nilai tstatistics yang didapat sebesar 5,694 dimana nilai tersebut lebih besar dari nilai t-table 
>1.96. Dapat diambil kesimpulan bahwa terdapat pengaruh yang signifikan antara pelatihan dengan kinerja karyawan dan hipotesis kedua $(\mathrm{H} 2)$ didukung. Hasil penelitian ini sama dengan penelitian yang dilakukan oleh Rahmawanti,Swasto dan Prasetya (2014) menyatakan bahwa lingkungan kerja berpengaruh positif dan signifikan terhadap kinerja karyawan.

\section{PENUTUP}

Penelitian ini bertujuan untuk mengetahui pengaruh kompensasi dan lingkungan kerja terhadap kinerja karyawan PT.Bank QNB Indonesia cabang SCBD, Sudirman, Jakarta Selatan. Kesimpulan yang diperoleh yaitusebagai berikut:

1. Kompensasi memiliki pengaruh yang positif dan tidak signifikan terhadap kinerja karyawan.

2. Lingkungan kerja memiliki pengaruh yang positif dan signifikan terhadap kinerja karyawan

Berdasarkan kesimpulan diatas, maka peneliti ingin memberikan saran untuk perusahaan bertujuan untuk kebaikan dan kemajuan perusahaan sebagai berikut:

1. Saran untuk perusahaan

Saran untuk perusahaan ini adalah perlunya ditingkatkan dari segi penambahan tunjangan karyawan seperti peningkatan dari gaji karyawan, bonus, dan insentif karyawan dan juga kesehatan karyawan demi kelangsungan perusahaan yang lebih baik dan pencapaian target yang maksimal

2. Saran untuk Peneliti lain

Saran untuk peneliti lain adalah, peneliti dapat menambahkan jenis variabel yang lain selain variabel kompensasi dan lingkungan kerja agar mendapatkan hasil yang beragam dan meningkatkan kinerja karyawan pada perusahaan yang diteliti

\section{DAFTAR PUSTAKA}

Alex S. Nitisemito, 1996. Manajemen Personalia, Sumber Daya Manusia, Gholia Indonesia, Jakarta.

Alex S. Nitisemito. 2000. Manajemen Personalia: Manajemen Sumber Daya Manusia, Epd. 3. Ghalia Indonesia, Jakarta.

Alex S, Nitisemito, 2002, Manajemen Personalia, Jakarta: Ghalia Indonesia

Abdillah, W. \& Hartono, J. (2015). Partial Least Square (PLS): Alternatif Structural Equation Modeling (SEM) dalam Penelitian Bisnis. Yogyakarta: C.V Andi Offset

Aritonang,R. Lerbin. (1998). Penelitian Pemasaran Cetakan Pertama. Jakarta : UPT Universitas Tarumanagara

Aritonang, L. R. (2007). Riset Pemasaran Teori dan Praktik. Bogor : Ghalia Indonesia.

Barry, Render dan Jay Heizer. 2001. Prinsip-prinsip Manajemen Operasi : Operations Management. Jakarta : Salemba Empat

Bernardin and Russel. 2009. Human Resource Management. International Editions Upper Saddle River. New Jersey:Prentice Hall.

Emad Y. Masoud, PhD \& Tahreer Abu Hmeidan, MBA. 2013. The Effect of Perceived Work Environment on Frontline Employees' Service Recovery Performance: The Case of Four and Five Star Hotels in Jordan. European Scientific Journal. Vol. 9, No. 11. 
Firmandari, Nuraini. 2014. "Pengaruh Kompensasi Terhadap Kinerja Karyawan dengan Motivasi Kerja Sebagai Variabel Moderasi (Studi Pada Bank Syariah Mandiri Kantor Cabang Yogyakarta)". Jurnal EKBISI Vol. IX No. 1 hal. 25-34

Gibson, James L,dkk.(2009) , “ Organizations Behaviour, Structure, Processes”, New York: America

Hair, J. F., Hult, G. T. M., Ringle, C. M., \& Sarstedt, M. (2017). A primer on partial least squares structural equation modeling (PLS-SEM). Thousand Oaks,CA: Sage

Hasibuan,Malayu S.P,2003,Manajemen Sumber Daya Manusia, Edisi Revisi, Bumi Aksara, Jakarta

Hussein, A. S., (2015). Penelitian Bisnis dan Manajemen Menggunakan Partial

Khusnul Fikri dan Roky Apriansyah.(2018). Pengaruh Kompensasi Terhadap Kinerja Karyawan yang Dimediasi oleh Kepuasan Kerja pada CV.Pelita Mandiri V Pematang Reba. Jurnal Manajemen dan Bisnis Vol.7 No.1

Lukito, CM. (2016). Pengaruh Kemampuan dan Kompensasi terhadap Kinerja Karyawan Perusahaan Plastik Putera di Gombong. Agora Vol.4, No.1

Malhotra, N. K. (2010). Marketing Research (6th ed.). New Jersey: Pearson Education,inc.

Mathis, R.L.; dan Jackson, J.H. 2004. Human Resource Management. 10th ed. Singapore: Cencage Learning

Mangkunegara, A.P. (2009). Evaluasi Kinerja SDM. Cetakan keenam. Bandung: Refika Aditama

Muchtar. (2016). The Influence of Motivation and Work Environment on the Performance of Employees. SINERGI. Vol. 2 No. 2

R, C Kothari. 2004. Research Methodology: Methods and Techniques. New Delhi: New Age Publisher

Rachmawati,I.K. (2008). Manajemen Sumber Daya Manusia. Yogyakarta: Andi

Rani Sadzwina, Alini Gilang, S.H, MM, (2015). Pengaruh kompensasi terhadap kinerja karyawan (Studi Pada Hotel Kartika Chandra Jakart). Vol. 2 No. 1, April 2015 : Universitas Telkom.

Richard L. Daft (2000). Manajemen. Jakarta: PT Gelora Aksara Pratama.

Rivai, Veithzal. 2011, Manajemen Sumber Daya Manusia untuk Perusahaan: dari Teori ke Praktik, Jakarta : RajaGrafindo Persada

Robbins,S.P., \& Judge, T.A., (2002). Perilaku Organisasi Buku 2. Jakarta: Salemba 284

Robbins,S.P., \& Judge, T.A., (2008). Perilaku Organisasi Buku 2. Jakarta: Salemba Empat

Sekaran, U. \& Bougie,R. (2016). Research Methods for Business (6th ed.) Southern Gate,Chichester, West Sussex: John Wiley \& Sons,Ltd

Sedarmayanti. 2001. Sumber Daya Manusia dan Produktifitas Kerja. Bandung : Mandar Maju

Simamora Henry. 2004. Manajemen Sumber Daya Manusia. Yogyakarta : SIE YKPN

Sophia. 2008. Perilaku Organisasional. Yogyakarta : Andi Offset

Subekhi, A., \& Jauhar, M. (2012). Pengantar manajemen sumber daya manusia (MSDM). Jakarta: Prestasi Pustakaraya

Suprihati, 2014,Analisis Faktor-faktor Yang Mempengaruhi Kinerja Karyawan Perusahaan Sari Jati Di Sragen, Jurnal paradigma, Vol.12, no.1, ISSN 1693-0827

Vita Bernadine \& FX. Suwarto. 2015. Pengaruh Gaya Kepemimpinan, Budaya Organisasi, dan Lingkungan Kerja Terhadap Kinerja Guru dan Karyawan pada Yayasan Tri Asih Jakarta 
Sebastian dan Andani: Pengaruh Kompensasi Dan Lingkungan Kerja Terhadap Kinerja...

Wardani. 2009. Riset Sumber Daya Manusia. Jakarta : PT. Gramedia Pustaka Utama Wibowo, 2016. Manajemen Kinerja, Edisi Kelima, PT.Rajagrafindo Persada Jakarta14240.

Winardi, 2007 , Manajemen Kinerja, Jakarta, PT. RajaGrafindo Persada. Jakarta. 